\title{
Christopher Le Dantec
}

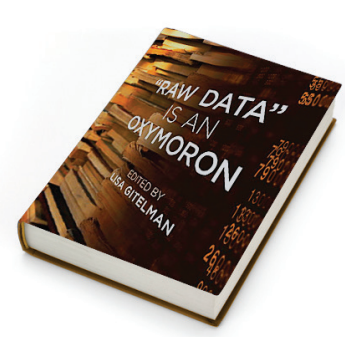

'Raw Data' Is an 0xymoron By Lisa Gitelman I am currently involved in a project called Cycle Atlanta where cyclists in the city are recording their rides in order to provide city planners with better data for use in developing new cycling facilities. One of the interesting questions that has come up is how do we balance data from very active cyclists so their rides do not skew analysis? Here, it's not just that the data is not raw-via the choices of what and how to collect it-but that cyclists actively create it with vested interests in influencing the design of public facilities.

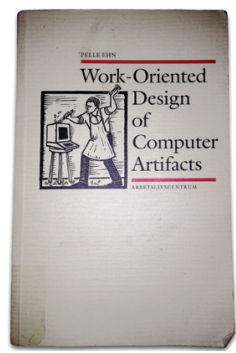

\section{Work-Oriented Design of} Computer Artifacts By Pelle Ehn Returning to the Scandinavian roots of participatory design, Ehn frames PD as a discipline focused on empowerment and engaging with professional practice (as opposed to reductions to Taylorian productivities and efficiencies). With my current work more directly confronting challenges around new forms of civic engagement, there are interesting parallels with the kind of deskilling of the workforce that PD was responding to and a kind of deskilling of community membership resulting from the focus on data- and appreliant modes of community and civic engagement. What, in essence, does a design intervention look like that takes as its goal emancipatory politics and the preservation of the practice of community membership?

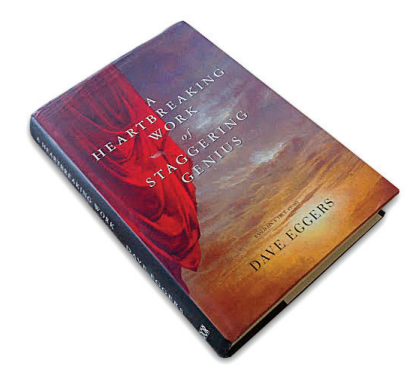

A Heartbreaking Work of Staggering Genius By Dave Eggers This has been on my to-read list for a decade and has finally shouldered its way onto my nightstand.

Player Piano By Kurt Vonnegut "If it weren't for the people, the god-damn

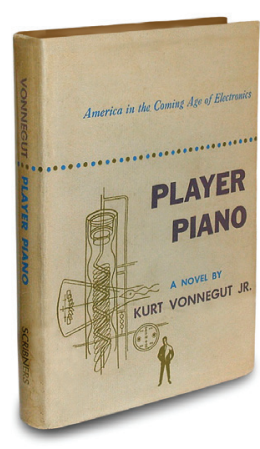

people" said Finnerty, "always getting tangled up in the machinery. If it weren't for them, the world would be an engineer's paradise." Returning to an old favorite, and running with a theme around my present fixation on civic engagement, digital democracy, and the present adoration of data (especially of the big variety) and the people who keep getting tangled up in all of it.

\section{(1) Christopher Le Dantec is} an assistant professor of digital media in the School of Literature, Media, and Communication at Georgia Tech.

$\rightarrow$ ledanteclagatech.edu

\section{"Ehn frames PD as a discipline focused on empowerment and engaging with professional practice."}

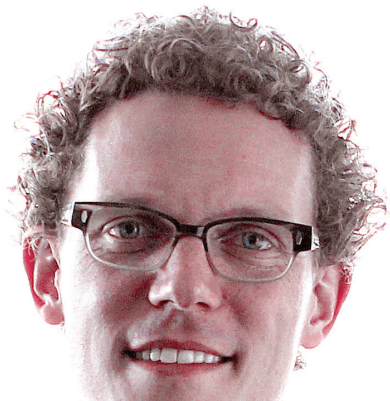

